BNL-113348-2016-JA

File \# 94301

\title{
Novel Effects of Compressed CO2 Molecules on Structural Ordering and Charge Transport in Conjugated Poly(3-hexylthiophene) Thin Films
}

\author{
Naisheng Jiang, Levent Sendogdular, Mani Sen, \\ Maya K. Endoh, Tadanori Koga, Masafumi Fukuto, \\ Bulent Akgun, Sushil K. Satija, and Chang-Yong Nam
}

Submitted to Langmuir

October 2016

Photon Sciences Department

Brookhaven National Laboratory

\author{
U.S. Department of Energy \\ USDOE Office of Science (SC), \\ Basic Energy Sciences (BES) (SC-22)
}

Notice: This manuscript has been authored by employees of Brookhaven Science Associates, LLC under Contract No. DE- SC0012704 with the U.S. Department of Energy. The publisher by accepting the manuscript for publication acknowledges that the United States Government retains a non-exclusive, paid-up, irrevocable, world-wide license to publish or reproduce the published form of this manuscript, or allow others to do so, for United States Government purposes. 


\section{DISCLAIMER}

This report was prepared as an account of work sponsored by an agency of the United States Government. Neither the United States Government nor any agency thereof, nor any of their employees, nor any of their contractors, subcontractors, or their employees, makes any warranty, express or implied, or assumes any legal liability or responsibility for the accuracy, completeness, or any third party's use or the results of such use of any information, apparatus, product, or process disclosed, or represents that its use would not infringe privately owned rights. Reference herein to any specific commercial product, process, or service by trade name, trademark, manufacturer, or otherwise, does not necessarily constitute or imply its endorsement, recommendation, or favoring by the United States Government or any agency thereof or its contractors or subcontractors. The views and opinions of authors expressed herein do not necessarily state or reflect those of the United States Government or any agency thereof. 


\title{
Novel effects of compressed $\mathrm{CO}_{2}$ molecules on structural
}

\section{ordering and charge transport in conjugated poly(3-}

\author{
hexylthiophene) thin films
}

Naisheng Jiang ${ }^{\dagger}$, Levent Sendogdular ${ }^{\dagger}$, Mani Sen ${ }^{\dagger}$, Maya K. Endoh ${ }^{\dagger}$, Tadanori Koga ${ }^{\dagger,},{ }^{+,}$, Masafumi Fukuto ${ }^{\S}$, Bulent Akgun ${ }^{\nabla}$, Sushil K. Satija" and Chang-Yong Nam ${ }^{\perp, *}$

${ }^{\dagger}$ Department of Materials Science and Chemical Engineering, Stony Brook University, Stony Brook, NY 11794-2275, USA

${ }^{\ddagger}$ Department of Chemistry, Stony Brook University, Stony Brook, NY 11794-3400, USA


USA

${ }^{\nabla}$ Department of Chemistry, Bogazici University, Bebek, Istanbul 34342, Turkey

"Center for Neutron Research, National Institute of Standards and Technology, Gaithersburg, MD 20899, USA

${ }^{\perp}$ Center for Functional Nanomaterials, Brookhaven National Laboratory, Upton, NY 11973-5000, USA 


\section{ABSTRACT}

We report the effects of compressed $\mathrm{CO}_{2}$ molecules as a novel plasticization agent for poly(3hexylthiophene) (P3HT) conjugated polymer thin films. In-situ neutron reflectivity experiment demonstrated the excess sorption of $\mathrm{CO}_{2}$ molecules in the P3HT thin films (about $40 \mathrm{~nm}$ in thickness $)$ at low pressure $(P=8.2 \mathrm{MPa})$ under the isothermal condition of $T=36{ }^{\circ} \mathrm{C}$, which is far below the polymer bulk melting point. The results evidenced that these $\mathrm{CO}_{2}$ molecules accelerated the crystallization process of the polymer on the basis of ex-situ grazing incidence Xray diffraction measurements after drying the films via rapid depressurization to atmospheric pressure: not only the out-of-plane lamellar ordering of the backbone chains but also intra-plane $\pi-\pi$ stacking of the side chains were significantly improved, when compared to those in the control P3HT films subjected to conventional thermal annealing (at $T=170{ }^{\circ} \mathrm{C}$ ). Electrical measurements elucidated that the $\mathrm{CO}_{2}$-annealed P3HT thin films exhibited enhanced charge carrier mobility along with decreased background charge carrier concentration and trap density compared to those in the thermally annealed counterpart. This is attributed to the $\mathrm{CO}_{2}$-induced increase in polymer chain mobility that can drive the detrapping of molecular oxygen and healing of conformational defects in the polymer thin film. Given the universality of the excess sorption of $\mathrm{CO}_{2}$ regardless of the type of polymers, the present findings suggest that the $\mathrm{CO}_{2}$ annealing near the critical point can be useful as a robust processing strategy for improving structural and electrical characteristics of other semiconducting conjugated polymers and related systems such as polymer: fullerene bulk heterojunction films. 


\section{INTRODUCTION}

Conjugated polymers are of great scientific interest due to their potential for a variety of applications in organic electronic devices including solar cells ${ }^{1-3}$ and field effect transistors $(\text { FETs })^{4-5}$. Poly(thiophene)s, such as poly(3-hexylthiophene) (P3HT), are one of the major costeffective functional conducting polymer families that have been widely used, owing to their relatively high stability, high conductivity, and wide visible-light absorption. ${ }^{6-7}$ In the polymerbased organic devices, charge transport and optical properties strongly depend on molecular structures, chain orientations, and the degree of crystallinity in the active polymer layers, consequently affecting the overall device performances. ${ }^{5,-8}$ For example, enhanced charge carrier mobility and device performance can be achieved by improving molecular ordering and chain alignments of conjugated polymers, since charge transfer along the polymer backbone and $\pi-\pi$ stacking direction are several orders of magnitude more efficient than that along insulating side chains. ${ }^{6-7,9}$ For this reason, the understanding of self-assembly processes in semicrystalline conducting polymer thin films, such as poly(thiophene)s, is of great value not only for fundamental polymer physics, but also for industrial applications as in organic electronic devices.

A spin-coating process is the most common way to prepare smooth and uniform conjugated polymer thin films for device fabrication. Resultant conjugated polymer films are confined between various interfaces, i.e., the polymer-air interface and the polymer-substrate interface. However, the fast solvent evaporation during the spin-coating process often leads to highly stressed and distorted chain conformations, which are far from their equilibrium. Various postcoating annealing procedures, including thermal and/or solvent annealing ${ }^{10-17}$, have been therefore required to achieve the optimized morphologies from the non-equilibrium poly(thiophene) or other $\pi$-conjugated spin-cast films in order to enhance their eventual device 
performance. However, high temperature annealing above the bulk melting temperature $\left(T_{\mathrm{m}}\right)$ of high molecular weight $\mathrm{P} 3 \mathrm{HT}\left(T_{\mathrm{m}} \sim 240{ }^{\circ} \mathrm{C}\right.$, regioregular) may lead to a strong performance degradation in the P3HT-based device ${ }^{15-16}$. Although "mild" annealing at temperatures between $T_{\mathrm{m}}$ and the glass transition temperatures $\left(T_{\mathrm{g}}\right)$ of $\mathrm{P} 3 \mathrm{HT}\left(T_{\mathrm{g}} \sim 10{ }^{\circ} \mathrm{C}\right)$ can also facilitate the reorganization of $\mathrm{P} 3 \mathrm{HT}$ crystals from the non-equilibrium state to more thermodynamically stable forms with improved crystalline ordering ${ }^{12,18-19}$, it often suffers from relatively low crystallinity and slow crystallization kinetics due to the limited chain mobility, subsequently affecting optical (light absorption) and electrical (charge mobility) properties in P3HT devices. While introducing solvent molecules in a polymer matrix as a plasticizer has shown a strong ability to enhance the chain mobility, crystallinity, and resulting charge transport properties in P3HT thin films ${ }^{5,13,20-22}$, the use of organic solvents can raise environmental concerns. In addition, the crystallization of $\mathrm{P} 3 \mathrm{HT}$ under solvent environment is complicated (which requires fine optimization of the volume ratio of added solvent, aging time, polymer concentration etc.), and the choice of solvents is extremely limited ${ }^{23}$. Moreover, solvents can dissolve polymer chains or cause undesirable morphologies in spin-coated P3HT films, such as dewetting from substrates ${ }^{24-}$ ${ }^{25}$. Hence, an alternative post-coating process for conjugated polymers is highly desirable for further development of polymer-based electronic devices.

Compressed $\mathrm{CO}_{2}$ gas $\left(T_{\mathrm{c}}=31.1^{\circ} \mathrm{C}\right.$ and $\left.P_{\mathrm{c}}=7.38 \mathrm{MPa}\right)$ is one of the most promising "green" plasticization agents alternative to hazardous organic solvents. ${ }^{26}$ In the case of thin film polymers, several groups have shown that the excess sorption of $\mathrm{CO}_{2}$ molecules occurs near the critical point where the density fluctuations of $\mathrm{CO}_{2}$ molecules becomes strongly correlated and maximum (known as the "density fluctuation ridge" ${ }^{27}$ or the Widom line ${ }^{28}$ ) regardless of the choice of polymers ${ }^{29-38}$. In general, the ridge emanates from the critical point, where the 
amplitude of the density fluctuations diverges and separates the more liquid-like and more gaslike regions in the supercritical region ${ }^{27,39}$. The vapor line below the critical point extends into the supercritical region due to a "memory effect", and the extended line is called the ridge. This ridge is not specific to $\mathrm{CO}_{2}$, but a general feature for other substances, such as $\mathrm{H}_{2} \mathrm{O}, \mathrm{CF}_{3} \mathrm{H}$, and $\mathrm{Ar}^{39}$. It is also known that the ridge corresponds to a maximum or minimum of thermal conductivity $^{40}$, sound velocity ${ }^{41}$, and partial molar volumes ${ }^{42-43}$. In addition, the rate constants or equilibrium constants of various chemical reactions in supercritical fluids show maxima, minima or inflection points at the ridge ${ }^{43}$. Interestingly, for polymer thin films subjected to the $\mathrm{CO}_{2}$ treatment, it was found that the functional form of the anomalous swelling amplitude of the polymer exactly followed that of calculated density fluctuations in a pure $\mathrm{CO}_{2}$ phase as functions of temperature and pressure ${ }^{29-30}$. Moreover, the plasticization effect associated with the excess $\mathrm{CO}_{2}$ sorption can greatly enhance the chain mobility and crystallization kinetics of glassy/semicrystalline polymers by lowering their bulk $T_{\mathrm{g}}$ and $T_{\mathrm{m}}$, especially at the vicinity of polymer air or polymer-solid interfaces ${ }^{29-31,44-53}$. Another unique feature of $\mathrm{CO}_{2}$ annealing is ability to dry $\mathrm{CO}_{2}$-exposed films via a rapid quench to atmospheric pressure without forming micron-sized voids ${ }^{49}$.

In this article, we utilize compressed $\mathrm{CO}_{2}$ gas near the critical point as a low-temperature, environmentally-friendly, and robust plasticization agent to improve the self-organization process of P3HT thin films. In-situ neutron reflectivity experiments demonstrated that the swelling isotherm of the P3HT thin film at $T=36{ }^{\circ} \mathrm{C}$ showed a maximum at the density fluctuation ridge (i.e., $P=8.2 \mathrm{MPa}$ ). We then characterized the $\mathrm{CO}_{2}$-treated and subsequently dried P3HT thin films using ex-situ grazing incidence X-ray diffraction and atomic force microscopy techniques. The X-ray diffraction results showed that not only the out-of-plane 
lamellar stacking but also the in-plane $\pi-\pi$ stacking are improved simultaneously, resulting in a larger crystalline size in the $\mathrm{CO}_{2}$-treated P3HT films compared to the P3HT films thermallyannealed at a higher temperature. We finally characterized the electrical properties of the $\mathrm{CO}_{2}{ }^{-}$ treated $\mathrm{P} 3 \mathrm{HT}$ thin film and found that the $\mathrm{CO}_{2}$ treatment increased the hole mobility in P3HT by $\sim 500 \%$ compared to the thermally annealed counterpart, while also decreasing the charge trap density and high background charge carrier concentration by similar magnitudes. These improvements in charge transport properties are attributed to the release of trapped oxygen molecules and associated charge traps from the P3HT film by $\mathrm{CO}_{2}$ annealing, highlighting the potential of the $\mathrm{CO}_{2}$ process for improving electrical performance of semicrystalline conducting polymers.

\section{EXPERIMENTAL SECTION}

Sample Preparation. Regioregular P3HT was purchased from American Dye Source Inc. with a number-average molecular mass of $M_{\mathrm{n}}=69 \mathrm{kDa}$ and an approximate regioregularity of 96 $\%$. The $T_{\mathrm{g}}$ and $T_{\mathrm{m}}$ were determined to be $12{ }^{\circ} \mathrm{C}$ and $239^{\circ} \mathrm{C}$, respectively, by differential scanning calorimetry (DSC). Silicon ( $\mathrm{Si}$ ) substrates were first cleaned using ultrasonic treatment in detergent and acetone, and then subjected to an immersion in a hot piranha solution (i.e., a mixture of $\mathrm{H}_{2} \mathrm{SO}_{4}$ and $\mathrm{H}_{2} \mathrm{O}_{2}$, caution: a piranha solution is highly corrosive upon contact with skin or eyes and is an explosion hazard when mixed with organic chemicals/materials; extreme care should be taken when handing it) for $30 \mathrm{~min}$, and were subsequently rinsed with deionized water thoroughly. The piranha solution-cleaned Si wafers were further immersed in an aqueous solution of hydrogen fluoride (HF) for $30 \mathrm{~s}$ to remove an oxide layer. X-ray reflectivity result showed that a thin oxide $\left(\mathrm{SiO}_{\mathrm{x}}\right)$ layer of $\sim 1 \mathrm{~nm}$ in thickness with a surface roughness of less than 
$0.3 \mathrm{~nm}$ was reproduced even after HF etching, possibly due to atmospheric oxygen and moisture, as reported previously ${ }^{54}$. Thin P3HT films with a fixed thickness of approximately $40 \mathrm{~nm}$ were prepared onto the cleaned Si substrates by spin-coating from chlorobenzene solutions at room temperature with a rotation speed of $2500 \mathrm{rpm}$. The average thicknesses of the spin-cast P3HT thin films were measured with an ellipsometer (Rudolf Auto EL-II) with a fixed refractive index of 1.45. All the spin-coated P3HT films kept under vacuum (below $10^{-3}$ Torr) at $25^{\circ} \mathrm{C}$ for $24 \mathrm{~h}$ before the $\mathrm{CO}_{2}$ processing and the dried samples were then transferred into a high-pressure cell ${ }^{30}$ immediately for $\mathrm{CO}_{2}$ exposure. As will be discussed later, the neutron reflectivity experiments demonstrate that the $\mathrm{CO}_{2}$ exposure at the density fluctuation ridge condition (i.e., $P=8.2 \mathrm{MPa}$ and $\left.T=36^{\circ} \mathrm{C}\right)^{27}$ for $24 \mathrm{~h}$ is satisfactory to achieve an improved ordered structure in P3HT. After the $\mathrm{CO}_{2}$ exposure, the chamber was quenched to atmospheric pressure either rapidly with a quench rate of ca. $50 \mathrm{MPa} / \mathrm{min}$ ("rapid" quench), or slowly with a quenching rate of ca. 0.15 $\mathrm{MPa} / \mathrm{min}$ ) ("slow" quench) to see whether the polymer crystalline structure is melted in $\mathrm{CO}_{2}$, since the quench rates control the resulting morphology, as previously observed in poly(ethylene oxide) thin films ${ }^{52}$. As shown in Supporting Information (Figure S1), the grazing incidence x-ray diffraction results reveal no significant differences between the two quenching rates, implying the $\mathrm{CO}_{2}$ treatment at the given pressure conditions up to $10 \mathrm{MPa}$ does not melt the P3HT chains. Instead, the $\mathrm{CO}_{2}$ molecules act as a plasticization agent ${ }^{50,52,55-56}$, facilitating the crystallization process. For a comparison, we also treated the P3HT thin films via a conventional high temperature annealing at $170{ }^{\circ} \mathrm{C}$ for $24 \mathrm{~h}$ under vacuum $\left(\sim 10^{-3} \mathrm{Torr}\right)$, followed by rapid quench to room temperature. 
In-situ Neutron Reflectivity. With a large penetration depth, neutron reflectivity (NR) is an ideal tool to monitor the in-situ thickness, composition, and interfacial structure of polymer thin films immersed in fluids or gases, under high pressure in thick walled vessels ${ }^{30,57}$. The in-situ swelling behavior of the P3HT thin films in $\mathrm{CO}_{2}$ was measured by NR. Approximately $40 \mathrm{~nm}-$ thick P3HT thin films were prepared on 3-inch Si wafers with identical cleaning and surface treatment as described above. Specular NR measurements were performed at the NG-7 reflectometer, National Institute of Standards and Technology Center for Neutron Research (NCNR). The wavelength $\left(\lambda_{\mathrm{N}}\right)$ of the neutron beam was $0.47 \mathrm{~nm}$ with $\Delta \lambda_{\mathrm{N}} / \lambda_{\mathrm{N}}=2.5 \%$. The details of the high-pressure NR experiments have been described elsewhere ${ }^{30}$. The NR experiments were conducted under the isothermal condition $\left(T=36^{\circ} \mathrm{C}\right)$ with elevated pressures up to $P=10.1 \mathrm{MPa}$. Temperature and pressure stabilities during the NR measurements were controlled within an accuracy of $\pm 0.1^{\circ} \mathrm{C}$ and $\pm 0.2 \%$, respectively. The P3HT thin films were exposed to $\mathrm{CO}_{2}$ for up to $1 \mathrm{~h}$ prior to data acquisition. The scattering length density $(S L D)$ values of $\mathrm{CO}_{2}$, which vary from $0.0004 \times 10^{-4}$ to $1.75 \times 10^{-4} \mathrm{~nm}^{-2}$ in the pressure range of $0.1 \mathrm{MPa} \leq P \leq$ 10.1 $\mathrm{MPa}$ at $T=36^{\circ} \mathrm{C}$, were calculated based on the density of $\mathrm{CO}_{2}$ obtained by the equation of state $^{58}$. The NR data was acquired by successively increasing pressure and then slowly decreasing pressure. Since the background scattering from a pure $\mathrm{CO}_{2}$ phase increases dramatically near the critical point ${ }^{29-30}$, we measured the scattering from the pure fluid phase (i.e., the long-range density fluctuations) for the respective pressure condition. The NR data corrected for the background scattering was analyzed by comparing the observed reflectivity curves with the calculated ones based on model SLD profiles having three fitting parameters for each layer: film thickness, $S L D$, and roughness between the $\mathrm{CO}_{2}$ and polymer layers represented as a 
Gaussian function ${ }^{59}$. It should be noted that we also included the thin $\mathrm{SiO}_{2}$ layer of $\sim 1 \mathrm{~nm}$, which was determined by X-ray reflectivity, for the NR fitting.

Grazing Incidence X-ray Diffraction. Grazing incidence X-ray diffraction (GIXD) measurements for the $\mathrm{CO}_{2}$-treated and thermally annealed P3HT thin films were carried out at the X9 beamline $(\lambda=0.0918 \mathrm{~nm}$ and $\mathrm{E}=13.5 \mathrm{keV})$ at the National Synchrotron Light Source (NSLS), Brookhaven National Laboratory. Two-dimensional scattering patterns were collected by using a MAR-CCD area detector. In order to see the differences in the microdomain structures between the topmost surface and the rest of the film, two different incident angles $(\alpha)$ were utilized: (i) $\alpha=0.08^{\circ}$, which is just below the critical angle $\left(\alpha_{\mathrm{c}}\right)$ of the total external reflection for P3HT $\left(\alpha_{\mathrm{c}}=0.12^{\circ}\right)$ such that the electric field intensity decays exponentially into the film, and thereby scattering intensity is dominated by the surface area of $\sim 10 \mathrm{~nm}$ depth; (ii) $\alpha=0.16^{\circ}>\alpha_{\mathrm{c}}$, where the X-ray penetration depth exceeds the film thickness such that we can obtain information on the average structures over the entire film. We denote the first experimental configuration as the "surface-mode" and the second one as the "film-mode" hereafter. All the experiments were carried out at room temperature under vacuum, and the exposure time for all the measurements was fixed to $300 \mathrm{sec}$.

X-ray Reflectivity Measurements. The specular X-ray reflectivity (XR) measurements were performed using an X-ray reflectometer (Bruker, D8 Advance) with $\mathrm{Cu} \mathrm{K} \alpha$ radiation at NCNR to study the expanded structures of the $\mathrm{CO}_{2}$-treated P3HT film after depressurization. The wavelength $\left(\lambda_{\mathrm{x}}\right)$ of the X-ray beam was $0.154 \mathrm{~nm}$ with $\Delta \lambda_{\mathrm{X}} / \lambda_{\mathrm{x}}=0.25 \%$. The XR data corrected 
for the background scattering was fitted using the Reflpak software package ${ }^{60}$ with a multilayer "slab" model for a $S L D$ profile.

Atomic Force Microscopy Measurements. The surface morphologies of the $\mathrm{CO}_{2}$-treated and thermally-annealed P3HT thin films were observed by atomic force microscopy (AFM) (Digital Nanoscope III and Bruker Bioscope Catalyst). A standard tapping mode was conducted in air using a cantilever with a frequency of $300 \mathrm{kHz}$ and a spring constant of $40 \mathrm{~N} / \mathrm{m}$. The scan rate was $0.5-1.0$ line/sec with scanning density of 512 lines per frame.

Device Electrical Measurements. For the electrical characterization, P3HT-chlorobenzene solutions were spin-cast $(\sim 40 \mathrm{~nm}$ in thickness) onto indium tin oxide (ITO)-glass substrates coated with $10 \mathrm{~nm}$-thick $\mathrm{MoO}_{3}$ hole transport layer deposited by thermal evaporation (Lesker PVD 75) at $\sim 1 \times 10^{-6}$ Torr. Each sample was then either thermally annealed or $\mathrm{CO}_{2}$-treated as described earlier. Top $10 \mathrm{~nm}$-thick $\mathrm{MoO}_{3}$ transport layer and $100 \mathrm{~nm}$-thick Au layer were then deposited on the processed P3HT film by thermal evaporation (at $\sim 1 \times 10^{-6}$ Torr) through a shadow mask $\left(1 \mathrm{~mm}\right.$ in diameter). Current density-voltage $(J-V)$ characterization for the $\mathrm{CO}_{2^{-}}$ treated and thermally-annealed P3HT films were performed by using an Agilent 4156C precision semiconductor parameter analyzer. The electrical properties were obtained by fitting $J-V$ profiles to the space charge limited conduction model. For each sample, 3-5 devices were measured for statistics.

\section{RESULTS AND DISCUSSION}

\section{Swelling experiments.}


We start with the pressure-dependent swelling behavior of the $\mathrm{P} 3 \mathrm{HT}$ thin film in $\mathrm{CO}_{2}$ via insitu NR measurements. Figure 1 (a) shows representative NR profiles for the P3HT film in $\mathrm{CO}_{2}$ at four different pressures under the isothermal condition $\left(T=36^{\circ} \mathrm{C}\right): P=0.1 \mathrm{MPa}($ air $), P=4.3$ $\mathrm{MPa}, P=8.2 \mathrm{MPa}$, and $P=10.1 \mathrm{MPa}$. It should be noted that the contributions from the density fluctuations of the pure $\mathrm{CO}_{2}$ phase (i.e., background) become significant near the ridge condition $\left(P=8.2 \mathrm{MPa}\right.$ at $\left.T=36{ }^{\circ} \mathrm{C}\right)$ and overwhelm the observed intensity at $q_{\mathrm{z}}>0.06 \AA^{-1} \cdot{ }^{29,48}$ The NR data corrected for the background scattering were fit by using the Reflpak software package ${ }^{60}$ with a multilayer "slab" model composed of the three fitting parameters for each layer. The thickness of the P3HT film, with the initial thickness of $43.6 \pm 0.4 \mathrm{~nm}$, gradually increases with increasing $\mathrm{CO}_{2}$ pressure, until it reaches to the maximum value of $47.8 \pm 0.4 \mathrm{~nm}$ at $P=8.2 \mathrm{MPa}$, i.e., the density fluctuation ridge $\mathrm{e}^{29-30}$. Figure 1 (b) shows the scattering length density (SLD) profiles of the P3HT obtained from the best fits. Since a simple boxlike shape profile could be approximated to represent the volume fraction profiles of the swollen P3HT film, it is reasonable to suppose that the solvent quality of $\mathrm{CO}_{2}$ for $\mathrm{P} 3 \mathrm{HT}$ is still poor ${ }^{61}$ even at the ridge condition. Figure 2 summarizes the linear dilation $\left(S_{\mathrm{f}}\right)$ of the 43 nm-thick P3HT film during the pressurization process. The $S_{\mathrm{f}}$ values were calculated by the equation, $S_{\mathrm{f}}=\left(L_{1}-L_{0}\right) / L_{0}$, where $L_{1}$ and $L_{0}$ are the measured thicknesses of the swollen and unswollen film, respectively. In the pressurization process, there is an anomalous peak in $S_{\mathrm{f}}$ near $P=8.2 \mathrm{MPa}$, which is attributed to the excess sorption of $\mathrm{CO}_{2}$ molecules at the density fluctuation ridge, as previously reported ${ }^{29-38}$. It is postulated that the origin of the anomalous expansion is attributed to the formation of a large correlation hole around " $\mathrm{CO}_{2}$-phobic" polymer chains (i.e., excluding the fluid molecules around the polymer chains). Within such solvation structures, the polymer chains are expanded as a thermodynamically stable state ${ }^{62-63}$. This expansion results in additional large solvent-density 
fluctuations around the polymer chain over a larger area relative to the correlation length of the solvent molecules, thus lowering the free energy of the $\mathrm{CO}_{2} /$ polymer system ${ }^{64}$.

To further investigate the swollen structure of the $\mathrm{P} 3 \mathrm{HT}$ films in $\mathrm{CO}_{2}$, the exposure time dependence of the swelling at the ridge condition $\left(T=36{ }^{\circ} \mathrm{C}\right.$ and $\left.P=8.2 \mathrm{MPa}\right)$ was studied. As shown in Figure 2 (b), the $S_{\mathrm{f}}$ value gradually decreased from $0.096 \pm 0.008$ to $0.053 \pm 0.008$ during the $\mathrm{CO}_{2}$ exposure, in contrast to a continuous increase in the $S L D$ values of the $\mathrm{P} 3 \mathrm{HT} / \mathrm{CO}_{2}$ mixture $\left(S L D_{\text {mix }}\right)$ up to $18.5 \mathrm{~h}$ of $\mathrm{CO}_{2}$ exposure. Note that the total mass of the $\mathrm{P} 3 \mathrm{HT} / \mathrm{CO}_{2}$ mixture per unit area, which is proportional to $L_{l} \times S L D_{\text {mix }}$, remained almost constant as a function of exposure time. Since the $S_{\mathrm{f}}$ values decrease with increasing exposure time, the increase in the $S L D$ value by $5 \%$ during the course of $\mathrm{CO}_{2}$ exposure (up to $22 \mathrm{~h}$ ) is not attributed to the additional absorption of $\mathrm{CO}_{2}$ molecules into the polymer matrix. Rather, this would be attributed to an increase in the density of P3HT film (i.e., the polymer chains become more crystallized) in the presence of the $\mathrm{CO}_{2}$ plasticizer. This is further supported by the pressure dependence of the roughness $(\sigma)$ at the polymer- $\mathrm{CO}_{2}$ interface obtained from the best fits (Figure 2c). While the determination of $\sigma$ near the ridge condition is difficult due to the high background scattering (i.e., the density fluctuations in the pure $\mathrm{CO}_{2}$ phase), the roughness tends to increase with increasing pressure up to $10.1 \mathrm{MPa}$. This indicates that the $\mathrm{CO}_{2}$ exposure at $T=36{ }^{\circ} \mathrm{C}$ does not induce the melting of the crystalline structures, which generally results in a much smoother surface, as previously reported in poly (ethylene oxide) thin films in $\mathrm{CO}_{2}^{52}$. Hence, the results overall support the $\mathrm{CO}_{2}$-induced crystallization of the P3HT chains.

\section{Investigation of Crystalline Phase.}


Figure 3 shows representative the two-dimensional GIXD results of the 43 nm-thick P3HT films obtained at the surface and film modes after exposed to $\mathrm{CO}_{2}$ at the ridge condition of $36{ }^{\circ} \mathrm{C}$ for $24 \mathrm{~h}$. As seen from the figure, well-defined three-order diffraction peaks, consisting of primary (100), secondary (200), and tertiary (300) peaks, were observed along the out-of-plane direction ( $q_{\mathrm{z}}$-direction), while a strong (010) peak, which corresponds to the intraplane $\pi-\pi$ stacking of P3HT chains, was observed in the in-plane $\left(q_{\mathrm{xy}}\right)$ direction. These GIXD results indicate the formation of a well-organized intraplane P3HT structure with lamellae oriented normal to the substrate surface (so called "edge-on" lamellae) during the $\mathrm{CO}_{2}$ exposure within the entire film. Note that the edge-on lamellar orientation was observed in all the $\mathrm{CO}_{2}$-treated P3HT films with different $\mathrm{CO}_{2}$ pressures (3 $\mathrm{MPa} \leq P \leq 10.1 \mathrm{MPa}$ ) and different exposure times ( $2 \mathrm{~h} \leq t \leq 48 \mathrm{~h}$ ), as well as in the thermal annealed films. We also confirmed that (i) no dewetting of the P3HT films occurs within at least $48 \mathrm{~h}$ of $\mathrm{CO}_{2}$ treatment or thermal annealing in vacuum, and (ii) the $\mathrm{CO}_{2}$-treated films after depressurization were stable for at least 1 month at room temperature and atmospheric pressure conditions. X-ray reflectivity results on the $\mathrm{CO}_{2}$-treated P3HT films at the ridge condition of $36{ }^{\circ} \mathrm{C}$ are summarized in Figure S2 (Supporting Information).

Figure 4 shows the one-dimensional GIXD profiles along the $q_{\mathrm{z}}$ and $q_{\mathrm{xy}}$ directions under the surface and film modes for the P3HT thin film after $\mathrm{CO}_{2}$ annealing at the ridge for $24 \mathrm{~h}$. The scattering intensity was normalized by the penetration depth of the respective X-ray probed region for a comparison. It is clear that the multiple peak intensities from the topmost surface region are much higher than those of the entire film region, indicating that the backbone orientation or the lamellar stacking in the out-of-plane direction is much improved at the surface region. Moreover, the peak intensity of the in-plane (010) reflection at the surface region is about 
4 times higher than that of the entire film, demonstrating the formation of more ordered $\pi-\pi$ stacking at the topmost surface. These results are consistent with previous reports that show the anomalous $\mathrm{CO}_{2}$ absorption into polymer thin films at the ridge condition is a surface effect due to the limited penetration power of the density fluctuating $\mathrm{CO}_{2}$ molecules in a viscous polymer matrix $^{29-30,48-49,65}$.

To further elucidate the effect of $\mathrm{CO}_{2}$ exposure on the P3HT structure, we fit the multiple peaks in the out-of-plane direction to a Gaussian function, determining the peak position $\left(q_{z}{ }^{*}\right)$ and peak width $(\beta)$, which are related with the lattice constant (i.e., the intermolecular backbone distance, $\left.a=2 \pi / q_{z}{ }^{*},\right)^{66}$ and the average crystalline size (or the coherent length, $L=(0.9 \lambda) /(\beta \cos \theta)$, with scattering angle $\theta)^{67}$. We found that the lattice constant of the $\mathrm{CO}_{2}$-treated P3HT film after $24 \mathrm{~h} \mathrm{CO}_{2}$ exposure at the ridge slightly decreased to $a=1.60 \pm 0.01 \mathrm{~nm}$, which is smaller than that of the thermally annealed film at $170{ }^{\circ} \mathrm{C}$ for $24 \mathrm{~h}(a=1.64 \pm 0.01 \mathrm{~nm})$. This result implies that the thiophene backbones or the lamellar stacking in the $\mathrm{CO}_{2}$-treated film is more compactly packed than that of the thermally-annealed film. In addition, the $L$ value of the $\mathrm{CO}_{2}$-treated film (at the ridge for $24 \mathrm{~h}$ ) was estimated to be $L=12.4 \pm 0.5 \mathrm{~nm}$, which is also greater than that of the thermally annealed film $\left(L=9.1 \pm 0.5 \mathrm{~nm}\right.$ ) (Figure 5a), again showing that $\mathrm{CO}_{2}$ treatment results in a more highly ordered $\mathrm{P} 3 \mathrm{HT}$ crystalline structure compared to the thermal annealing. Consistently, the (010) peak is also intensified after $24 \mathrm{~h}$ exposure of $\mathrm{CO}_{2}$ at the ridge condition compared to the thermally-annealed film, indicating a much improved intraplane $\pi$ - $\pi$ stacking after the $\mathrm{CO}_{2}$ process. These results suggest that the $\mathrm{CO}_{2}$ annealing at the ridge plays a crucial role as an effective plasticization agent to enhance the polymer chain mobility and hence prompt the reorganization of the $\mathrm{P} 3 \mathrm{HT}$ crystalline structures in both the out-of-plane and in-plane directions simultaneously. Given the lesser degree of structural reorganization observed in the 
thermally-annealed P3HT film despite its much higher processing temperature $\left(170{ }^{\circ} \mathrm{C}\right)$ than the $\mathrm{CO}_{2}$ treatment $\left(T=36^{\circ} \mathrm{C}\right)$ with a same annealing time $(24 \mathrm{~h})$, it is clear that the low-temperature $\mathrm{CO}_{2}$-annealing is much more effective in enhancing the crystalline order of P3HT thin films than conventional thermal annealing even when the process condition is far below the bulk $T_{\mathrm{m}}$.

AFM was used to further investigate the effect of $\mathrm{CO}_{2}$ annealing on the surface morphology of the P3HT thin films. Figure 6 shows the AFM height images of both the $\mathrm{CO}_{2}$-treated P3HT film at the ridge for $24 \mathrm{~h}$ and the thermally-annealed P3HT film $\left(T=170{ }^{\circ} \mathrm{C}\right.$ for $\left.24 \mathrm{~h}\right)$. As a comparison purpose, the as-cast P3HT film is also shown in the figure. As seen from the images, the surface of the as-cast P3HT film is featureless with a surface root-mean-square (RMS) roughness of $\sigma_{\mathrm{q}}=2.6 \mathrm{~nm}$, which is in line with previous report ${ }^{68}$. At the same time, nanoribbonlike structures are found in the phase images (see, Figure S3 in Supporting Information), which are attributed to the long-range lateral ordering of P3HT crystals ${ }^{68-69}$. After the as-cast film was thermally annealed at $170{ }^{\circ} \mathrm{C}$ for $24 \mathrm{~h}$, the surface RMS roughness increased to $\sigma_{\mathrm{q}}=6.1 \mathrm{~nm}$ due to the surface aggregation of the P3HT molecules into disk-type granular crystals (edge-on lamellae) (Figure 6 (b)). On the other hand, it was found that similar disk-type granular crystals were also formed after the $\mathrm{CO}_{2}$ annealing, but, with much more increased surface RMS roughness, as high as $\sigma_{\mathrm{q}}=10.8 \mathrm{~nm}$. This again suggests that the $\mathrm{CO}_{2}$ annealing is more effective in promoting larger P3HT crystalline aggregates with enhanced molecular ordering than the conventional thermal annealing.

\section{Electrical measurements.}

Finally, we discuss the effects of the improved stacking of P3HT chains on electrical properties. Hole-only charge transport properties were examined by measuring current density - 
voltage $(J-V)$ characteristics of the processed P3HT thin films sandwiched between bottom indium tin oxide (ITO)/ $\mathrm{MoO}_{3}$ and top $\mathrm{MoO}_{3} / \mathrm{Au}$ electrodes. Figure 7 shows the representative $J$ $V$ characteristics of the thermally-annealed and $\mathrm{CO}_{2}$-treated P3HT devices under dark ambient conditions (top). From the figure, it is apparent that the $\mathrm{CO}_{2}$-treated $\mathrm{P} 3 \mathrm{HT}$ at the ridge condition for $24 \mathrm{~h}$ shows more pronounced non-linear $J-V$ characteristic with increased conductance compared with the thermally annealed $\left(24 \mathrm{~h}\right.$ at $\left.170{ }^{\circ} \mathrm{C}\right) \mathrm{P} 3 \mathrm{HT}$ film. The corresponding double logarithmic plot (Figure 7 bottom) reveals that the thermally-annealed P3HT film largely follows the Ohmic conduction (i.e., slope $\sim 1$ ) within $2 \mathrm{~V}$ bias range, while the $\mathrm{CO}_{2}$-treated film displays a transition from the Ohmic to space charge limited conduction (SCLC, slope $\sim 2$ ) with transitioning voltage $\left(V_{T h}\right) \sim 0.3 \mathrm{~V}$. The conduction in the thermally-annealed P3HT film started deviating from the Ohmic behavior for $V>\sim 3 \mathrm{~V}$ range (i.e., $V_{T h}>3 \mathrm{~V}$ ) but did not fully converge to SCLC (data not shown), indicating a much larger background charge carrier density. ${ }^{70-72}$ The Mott-Gurney equation predicts that under the SCLC (either trap-free or with fully filled traps), $J$ increases quardratically with $V$ with following relation: ${ }^{70}$

$$
J=98 \varepsilon \text { oc } r \mu V 2 d 3 \text {, }
$$

where $\mu$ is the charge carrier mobility, $\varepsilon_{\mathrm{o}}$ is the vacuum permittivity, $\varepsilon_{\mathrm{r}}$ is the relative dielectric constant of the semiconductor ( $\sim 3$ for $\mathrm{P} 3 \mathrm{HT})$, and $d$ is the thickness of the semiconductor layer. From the SCLC-dominated bias region in Figure 7, we find that the hole mobility of the P3HT film $\mathrm{CO}_{2}$-treated at the ridge condition is enhanced to $\sim 3 \times 10^{-5} \mathrm{~cm}^{2} \mathrm{~V}^{-1} \mathrm{~s}^{-1}$, compared with $\sim 0.6 \times$ $10^{-5} \mathrm{~cm}^{2} \mathrm{~V}^{-1} \mathrm{~s}^{-1}$ in the thermally-annealed counterpart (Table 1 ). The mobility in the thermallyannealed P3HT was estimated from the lower-bound background carrier density corresponding to $V_{T h}=3 \mathrm{~V}$ and the measured Ohmic conductivity $(\sigma)$ for $V<3 \mathrm{~V}$ via the following relation: $:^{71-72}$

$$
\mu=89 d 2 \varepsilon 0 \varepsilon r \sigma V T h
$$


The higher hole mobility in the $\mathrm{CO}_{2}$-annealed P3HT compared with the thermally annealed sample can be attributed to the improved structural order in $\mathrm{P} 3 \mathrm{HT}$ after the $\mathrm{CO}_{2}$ processing, as discussed in the aforementioned NR and GIXD results that are consistent with previous studies reported by Kokubo and $\mathrm{Yang}^{73}$, who showed that the $\mathrm{CO}_{2}$-induced polymer chain mobility promoted a higher-order self-assembled structures in P3HT polymers. It should be emphasized that their $\mathrm{CO}_{2}$ process condition $\left(T=20{ }^{\circ} \mathrm{C}\right.$ and $\left.P=4.8 \mathrm{MPa}\right)$ is not as effective as our ridge condition so that their $\mathrm{CO}_{2}$ exposure times were extended up to $96 \mathrm{~h}$. It is noted that in our study the hole mobility enhancement was also accompanied by a near one order of magnitude reduction in charge carrier density $(n)$ to $\sim 7 \times 10^{16} \mathrm{~cm}^{-3}$ of the $\mathrm{CO}_{2}$-treated P3HT film from $\sim 3 \times$ $10^{17} \mathrm{~cm}^{-3}$ of the thermally annealed P3HT film, where $n$ was evaluated based on its relation to the threshold voltage $\left(V_{T h}\right)$ over which the low-bias Ohmic conduction was transitioning to SCLC as the contact-injected excess charge carriers started overwhelming the pre-existing background charge carriers: ${ }^{72}$

$$
n=98 \varepsilon 0 \varepsilon r e V T h d 2
$$

with $e$ being an elementary charge. Given the ambient air handling of our samples, molecular oxygen is expected to be responsible for the p-type doping of $\mathrm{P} 3 \mathrm{HT}$ and the increased background charge carrier density-oxygen molecules are known to interact with the thiophene rings in P3HT, affecting the charge carrier density as well as hole mobility through the charge transfer mechanism ${ }^{74-75}$. The decrease in the oxygen doping amount in P3HT as indicated by the reduced $V_{T h}{ }^{72,76-77}$ suggests that the $\mathrm{CO}_{2}$-induced higher polymer chain mobility allowed a more efficient release of oxygen molecules from the P3HT film.

We also found that the $\mathrm{CO}_{2}$-treated P3HT film exhibits a lowered change trap density $\left(N_{T}\right)$ compared with the thermally annealed counterpart. $N_{T}$ was estimated by fitting the high bias 
region of $J-V$ characteristics (Figure 8) to the Poole conduction model, where the charge transport is mediated by the continuous trapping and detrapping events of charge carriers among the closely spaced, adjacent trap sites, resulting in the following $J$ - $V$ relation: ${ }^{71,78}$

$$
J \propto \exp (e S 2 k T V d)
$$

with $k$ being the Boltzmann constant and $S$ the inter-trap spacing which is directly related to $N_{T}$ $\left(N_{T}=S^{-3}\right)$. As summarized in Table $1, N_{T}$ in the $\mathrm{CO}_{2}$ treated P3HT film is $\sim 2.4 \times 10^{21} \mathrm{~cm}^{-3}$, nearly one order of magnitude lower than that observed in the thermally-annealed P3HT film $(\sim 1.6 \times$ $\left.10^{22} \mathrm{~cm}^{-3}\right)$. In the case of organic semiconductor thin films, the existence of trap states localized in the bandgap was well documented ${ }^{22,79}$, and the structural and morphological defects, disorders, and impurities are typically responsible for the formation of charge traps. ${ }^{71,80}$ The significantly lower $N_{T}$ value in the $\mathrm{CO}_{2}$-treated film again indicates that the $\mathrm{CO}_{2}$ process induces a more significant polymer chain mobility compared with the thermal annealing, more efficiently remedying conformational disorders in polymers, as well as releasing molecular oxygen, both of which are known to be able to create charge traps.

\section{CONCLUSION}

We have investigated the effects of $\mathrm{CO}_{2}$ annealing near the critical point on the chain stacking structures in the spin-cast P3HT thin films. In-situ NR measurements revealed the excess sorption of $\mathrm{CO}_{2}$ molecules in the P3HT thin film at $T=36^{\circ} \mathrm{C}$ and $P=8.2 \mathrm{MPa}$, where the density fluctuations of $\mathrm{CO}_{2}$ become maximized. In addition, the $\mathrm{NR}$ data indicates that the $\mathrm{CO}_{2}$ molecules expedite the crystallization process rather than the melting of the crystalline structures. In order to further clarify the plasticization effect associated with the excess $\mathrm{CO}_{2}$ sorption on the crystalline structures, ex-situ GIXD and AFM experiments were performed after drying the films 
via rapid depressurization process. The results are intriguing to exhibit more enhanced out-ofplane lamellar stacking as well as the in-plane $\pi-\pi$ stacking along with a larger crystal size, when compared to the thermally-annealed P3HT counterpart. These results demonstrate that the $\mathrm{CO}_{2}$ near the critical point acts as a robust plasticization agent, significantly enhancing the polymer chain mobility and, therefore, improving the molecular ordering of polymer chains even at the temperature far below the bulk melting temperature. Electrical measurements further showed that the $\mathrm{CO}_{2}$-annealed P3HT films exhibited largely enhanced charge carrier mobility as well as decreased charge trap and background carrier densities, compared to the P3HT films subjected to thermal annealing. We postulate that these improvements in the electrical performance are attributed not only to the better crystalline ordering of the $\mathrm{CO}_{2}$-annealed P3HT films but also to the higher efficiency in alleviating trapped oxygen molecules and charge traps from the P3HT film due to the enhanced polymer chain mobility. Since $\mathrm{CO}_{2}$ is non-toxic and environmentally benign, and the excess sorption of $\mathrm{CO}_{2}$ molecules in polymer thin film is rather general regardless of the choice of polymers ${ }^{29-38}$, the use of compressed $\mathrm{CO}_{2}$ gas as a plasticization agent can be a robust, green processing method for improving the structural ordering and charge transport properties in conjugated polymer thin films used in organic electronic devices. Along the line, we are currently conducting the studies on the effect of the same $\mathrm{CO}_{2}$ annealing on conjugated polymer:fullerene bulk heterojunction films, and the summary will be reported in the near future. 


\section{FIGURES}

Figure 1. (a) NR profiles for the original $43 \mathrm{~nm}$ thick P3HT film at the four different pressures and $T=36{ }^{\circ} \mathrm{C}$. The solid lines correspond to the best fits to the data based on the corresponding $S L D$ profiles shown in (b).
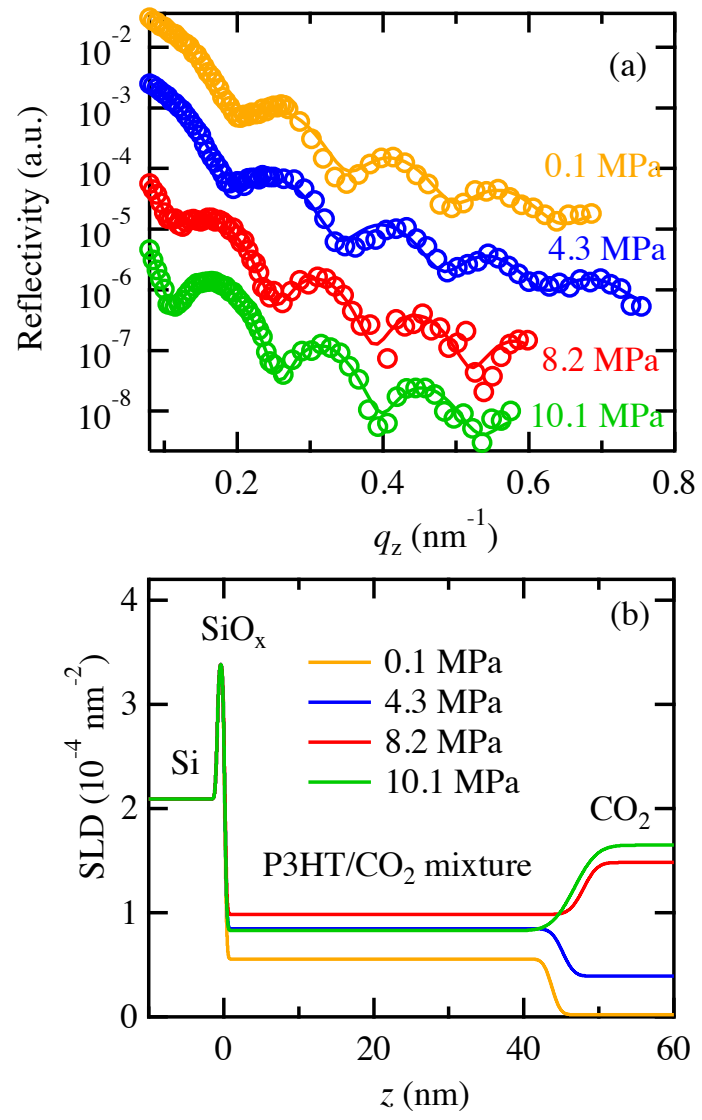
Figure 2. (a) $S_{\mathrm{f}}$ of the P3HT thin film as a function of pressure at the density fluctuation ridge ( $T$ $=36{ }^{\circ} \mathrm{C}$ and $P=8.2 \mathrm{MPa}$ ). The open circles correspond to the $S_{\mathrm{f}}$ in the pressurization process, while the solid triangles correspond to the $S_{\mathrm{f}}$ in the depressurization process. (b) $\mathrm{CO}_{2}$ exposure time dependence of $S_{\mathrm{f}}$ and $S L D$ of the P3HT thin film at the density fluctuation ridge. (c) Full width at half maximum (FWHM) roughness as a function of pressure at $T=36{ }^{\circ} \mathrm{C}$.
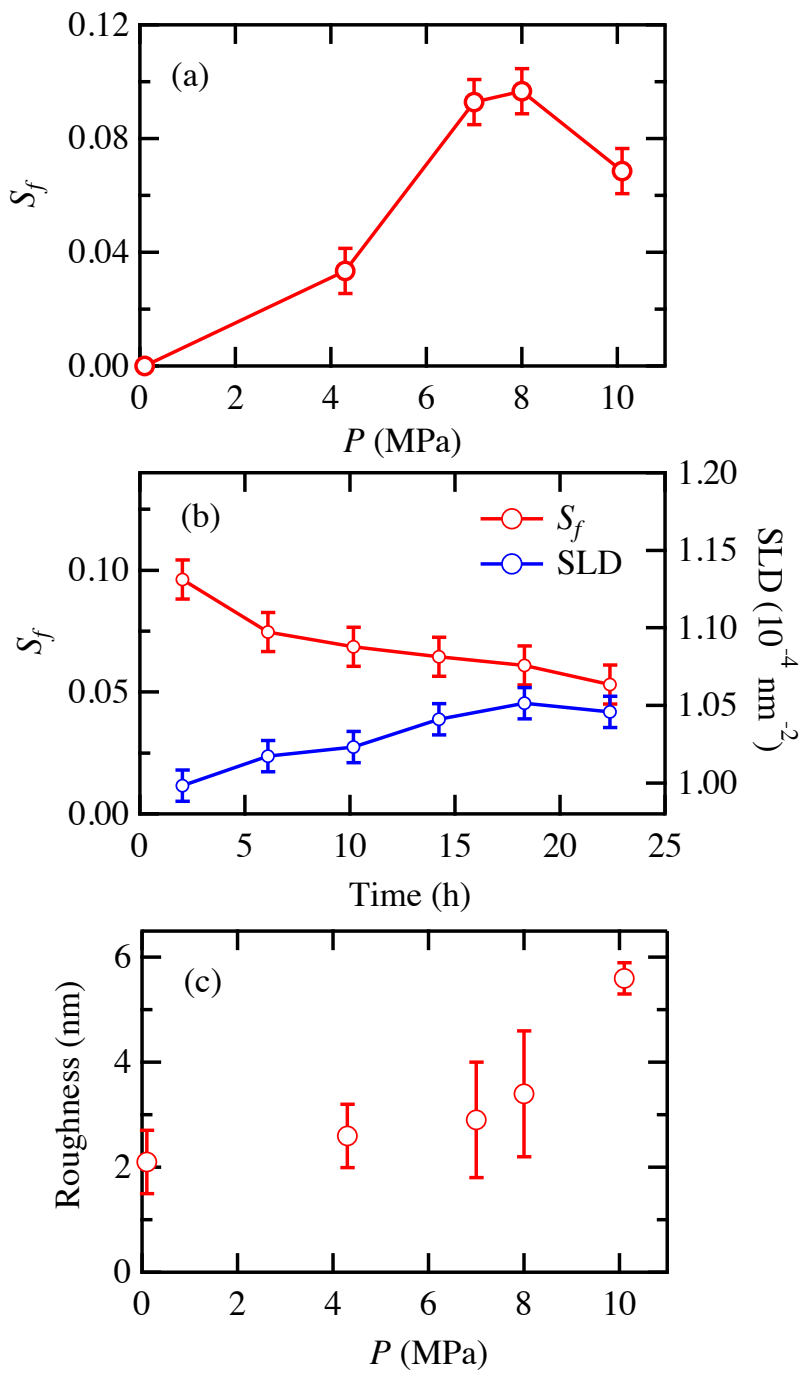
Figure 3. 2D GIXD images for the $\mathrm{CO}_{2}$-treated P3HT thin film (the original thickness of $43 \mathrm{~nm}$ ) after $\mathrm{CO}_{2}$ expose at the ridge for $24 \mathrm{~h}$ : (top) surface mode; (bottom) film mode with the same accumulation time (300 sec).

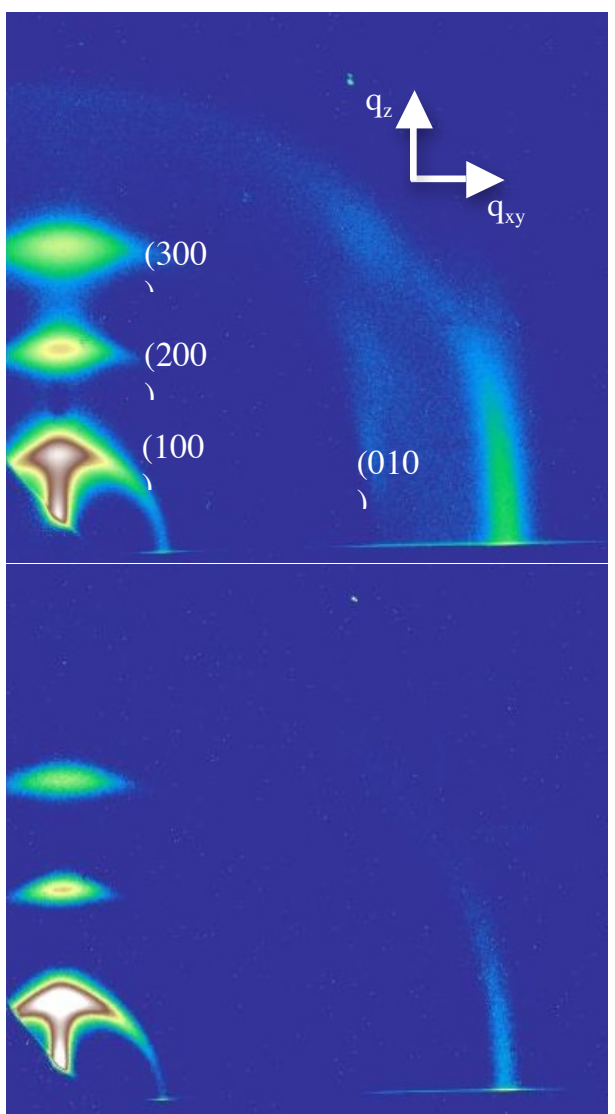


Figure 4. GIXD profiles of the P3HT thin film (the original thickness was $43 \mathrm{~nm}$ ) along (top) the $\mathrm{q}_{\mathrm{z}}$ and (bottom) $\mathrm{q}_{\mathrm{xy}}$ directions after the $\mathrm{CO}_{2}$ annealing at the ridge condition.
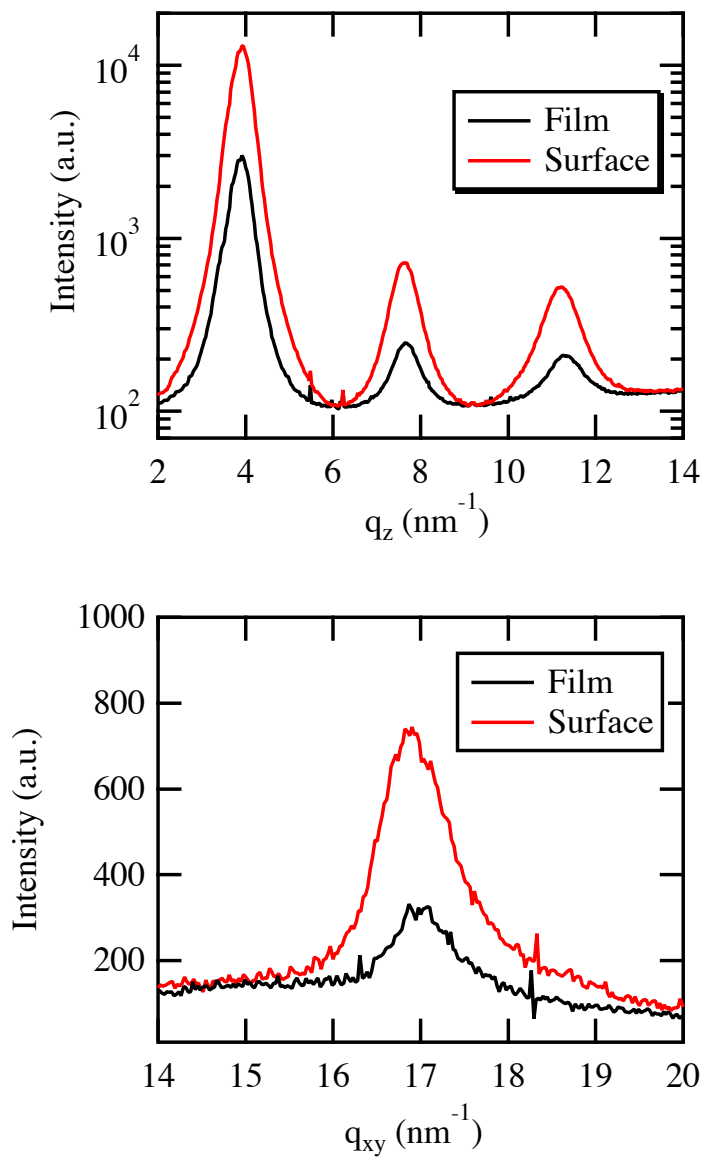
Figure 5. GIXD profiles of the P3HT thin film (the original thickness was $43 \mathrm{~nm}$ ) along (top) the $\mathrm{q}_{\mathrm{z}}$ and (bottom) $\mathrm{q}_{\mathrm{xy}}$ directions after the $\mathrm{CO}_{2}$ annealing at the ridge condition.
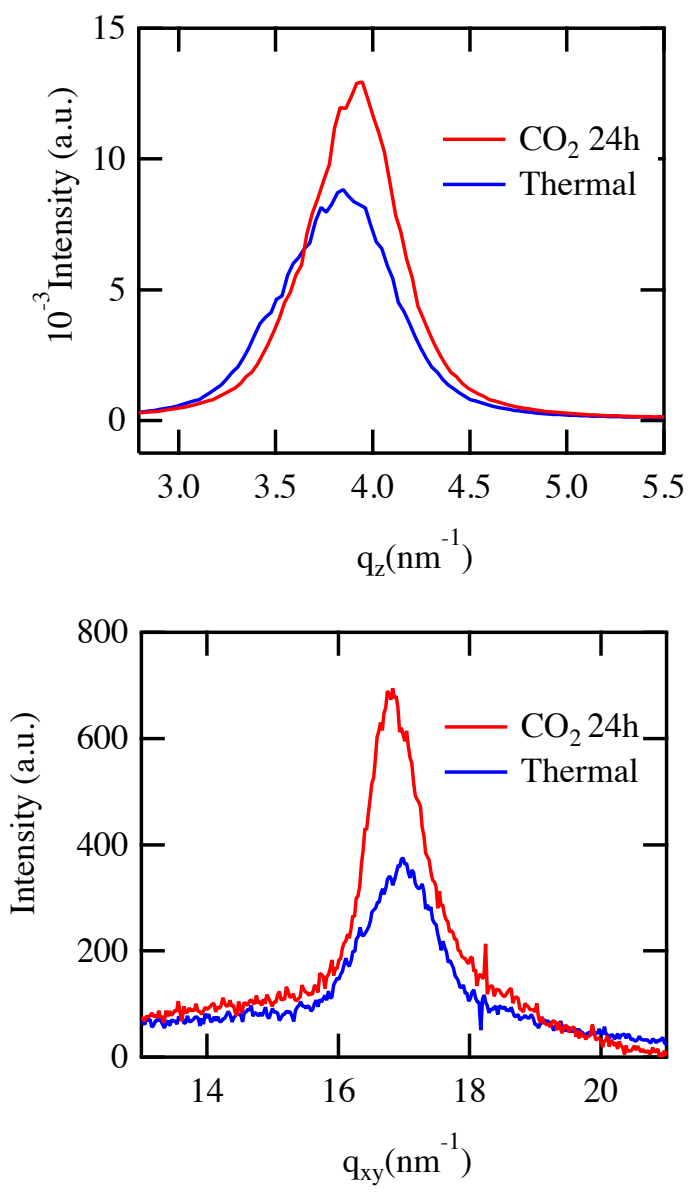
Figure 6. AFM height images of the $43 \mathrm{~nm}$-thick P3HT films after (a) spin-casting, (b) thermally annealed at $\mathrm{T}=170{ }^{\circ} \mathrm{C}$ for $24 \mathrm{~h}$ and (c) exposing to $\mathrm{CO} 2$ at the ridge condition for $24 \mathrm{~h}$. The height scales of all the images are $0-40 \mathrm{~nm}$. The corresponding cross-sectional height profiles of the images with larger scale are shown in (d).

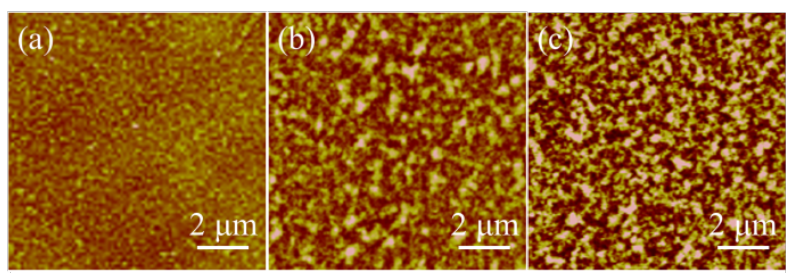

(d)
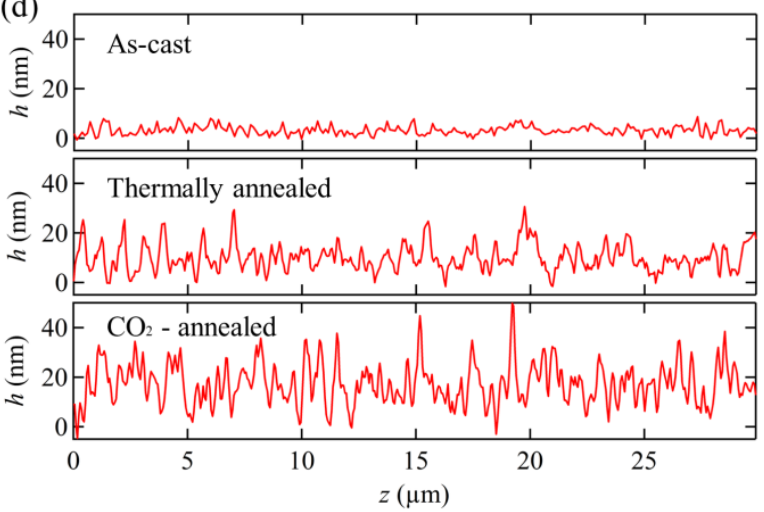
Figure 7. Representative $J$ - $V$ characteristics of thermally-annealed and $\mathrm{CO}_{2}$-treated $\mathrm{P} 3 \mathrm{HT}$ hole only devices, with top panel showing a linear plot and bottom a double-logarithmic plot. Dashed lines indicates regions dominated by Ohmic conduction $(V<\sim 0.3 \mathrm{~V})$ and SCLC $(V>\sim 0.3 \mathrm{~V})$, respectively.
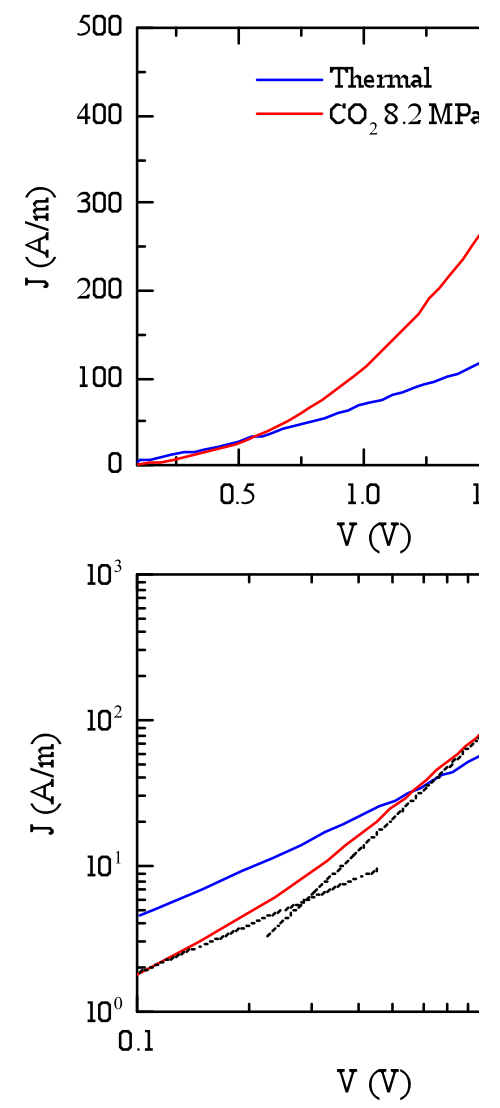
Figure 8. Representative semi-logarithmic $J$ - $V$ characteristics of thermally-annealed and $\mathrm{scCO}_{2}{ }^{-}$ treated P3HT hole only devices, indicating high bias linear regions fitted to the Poole conduction model.

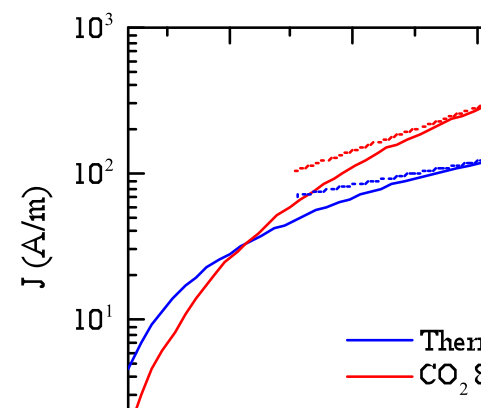


Table 1. Summary of charge transport parameters obtained from the analysis of $J-V$ characteristics.

\begin{tabular}{ccccc}
\hline Post-process & $m\left[\mathrm{~cm}^{2} \mathrm{~V}^{-1} \mathrm{~s}^{-1}\right]$ & $n\left[\mathrm{~cm}^{-3}\right]$ & $S[\mathrm{~nm}]$ & $N_{T}\left[\mathrm{~cm}^{-3}\right]$ \\
\hline Thermal & $6.3 \times 10^{-6}$ & $3.5 \times 10^{17}$ & 0.39 & $1.6 \times 10^{22}$ \\
& & & & \\
$\mathrm{CO}_{2}$ treatment & $3.0 \times 10^{-5}$ & $7.0 \times 10^{16}$ & 0.75 & $2.4 \times 10^{21}$ \\
& & & & \\
\hline
\end{tabular}


Supporting Information. The effect of $\mathrm{CO}_{2}$ quenching rates on the P3HT structures, X-ray reflectivity results before and after $\mathrm{CO}_{2}$ exposure, atomic force microscopy phase image of the P3HT film after exposing to $\mathrm{CO}_{2}$. This material is available free of charge on the ACS

Publications website at DOI: $\mathrm{xxx} / \mathrm{xxxx}$

\section{AUTHOR INFORMATION}

\section{Corresponding Authors}

*Email: tadanori.koga@ stonybrook.edu (T.K.) and cynam@bnl.gov (C.-Y.N)

\section{Notes}

The authors declare no competing financial interest.

\section{ACKNOWLEDGMENTS}

T. K. acknowledges partial financial supports from NSF Grants (CMMI-084626 and CMMI1332499). Use of the National Synchrotron Light Source was supported by the U.S. Department of Energy, Office of Science, Office of Basic Energy Sciences, under Contracts No. DE-AC0298CH10886. This research was in part carried out at the Center for Functional Nanomaterials of Brookhaven National Laboratory, which is supported by the U.S. Department of Energy, Office of Basic Energy Sciences, under Contract No. DE-SC0012704. 


\section{REFERENCES}

1. Brabec, C. J.; Sariciftci, N. S.; Hummelen, J. C. Plastic Solar Cells. Adv. Funct. Mater. 2001, $11(1), 15-26$.

2. Shaheen, S. E.; Brabec, C. J.; Sariciftci, N. S.; Padinger, F.; Fromherz, T.; Hummelen, J. C. 2.5\% efficient organic plastic solar cells. Appl. Phys. Lett. 2001, 78 (6), 841-843.

3. Hoppe, H.; Sariciftci, N. S. Organic solar cells: An overview. J Mater Res 2004, 19 (07), 1924-1945.

4. Sirringhaus, H.; Tessler, N.; Friend, R. H. Integrated Optoelectronic Devices Based on Conjugated Polymers. Science 1998, 280 (5370), 1741-1744.

5. Yang, H.; Shin, T. J.; Yang, L.; Cho, K.; Ryu, C. Y.; Bao, Z. Effect of Mesoscale Crystalline Structure on the Field-Effect Mobility of Regioregular Poly(3-hexyl thiophene) in Thin-Film Transistors. Adv. Funct. Mater. 2005, 15 (4), 671-676.

6. Bao, Z.; Dodabalapur, A.; Lovinger, A. J. Soluble and processable regioregular poly(3 hexylthiophene) for thin film field - effect transistor applications with high mobility. Appl Phys Lett 1996, 69 (26), 4108-4110.

7. Sirringhaus, H.; Brown, P. J.; Friend, R. H.; Nielsen, M. M.; Bechgaard, K.; LangeveldVoss, B. M. W.; Spiering, A. J. H.; Janssen, R. A. J.; Meijer, E. W.; Herwig, P.; de Leeuw, D. M. Two-dimensional charge transport in self-organized, high-mobility conjugated polymers. Nature 1999, 401 (6754), 685-688. 
8. Benanti, T. L.; Venkataraman, D. Organic Solar Cells: An Overview Focusing on Active Layer Morphology. Photosynthesis Research 2006, 87 (1), 73-81.

9. Sirringhaus, H.; Wilson, R. J.; Friend, R. H.; Inbasekaran, M.; Wu, W.; Woo, E. P.; Grell, M.; Bradley, D. D. C. Mobility enhancement in conjugated polymer field-effect transistors through chain alignment in a liquid-crystalline phase. Appl Phys Lett 2000, 77 (3), 406-408.

10. Li, G.; Shrotriya, V.; Huang, J.; Yao, Y.; Moriarty, T.; Emery, K.; Yang, Y. Highefficiency solution processable polymer photovoltaic cells by self-organization of polymer blends. Nat Mater 2005, 4 (11), 864-868.

11. Kim, Y.; Cook, S.; Tuladhar, S. M.; Choulis, S. A.; Nelson, J.; Durrant, J. R.; Bradley, D. D. C.; Giles, M.; McCulloch, I.; Ha, C.-S.; Ree, M. A strong regioregularity effect in selforganizing conjugated polymer films and high-efficiency polythiophene:fullerene solar cells. Nat Mater 2006, 5 (3), 197-203.

12. Joseph Kline, R.; McGehee, M. D.; Toney, M. F. Highly oriented crystals at the buried interface in polythiophene thin-film transistors. Nat Mater 2006, 5 (3), 222-228.

13. Li, G.; Yao, Y.; Yang, H.; Shrotriya, V.; Yang, G.; Yang, Y. "Solvent Annealing” Effect in Polymer Solar Cells Based on Poly(3-hexylthiophene) and Methanofullerenes. Adv Funct Mater 2007, 17 (10), 1636-1644.

14. Zhao, G.; He, Y.; Li, Y. 6.5\% Efficiency of Polymer Solar Cells Based on poly(3hexylthiophene) and Indene-C60 Bisadduct by Device Optimization. Adv Mater 2010, 22 (39), 4355-4358. 
15. Kim, Y.; Choulis, S. A.; Nelson, J.; Bradley, D. D. C.; Cook, S.; Durrant, J. R. Device annealing effect in organic solar cells with blends of regioregular poly(3-hexylthiophene) and soluble fullerene. Appl Phys Lett 2005, 86 (6), 063502.

16. Li, G.; Shrotriya, V.; Yao, Y.; Yang, Y. Investigation of annealing effects and film thickness dependence of polymer solar cells based on poly(3-hexylthiophene). J Appl Phys 2005, $98(4), 043704$.

17. Yang, H.; LeFevre, S. W.; Ryu, C. Y.; Bao, Z. Solubility-driven thin film structures of regioregular poly(3-hexyl thiophene) using volatile solvents. Appl Phys Lett 2007, 90 (17), 172116.

18. Verploegen, E.; Mondal, R.; Bettinger, C. J.; Sok, S.; Toney, M. F.; Bao, Z. Effects of Thermal Annealing Upon the Morphology of Polymer-Fullerene Blends. Adv Funct Mater 2010, 20 (20), 3519-3529.

19. Agostinelli, T.; Lilliu, S.; Labram, J. G.; Campoy-Quiles, M.; Hampton, M.; Pires, E.; Rawle, J.; Bikondoa, O.; Bradley, D. D. C.; Anthopoulos, T. D.; Nelson, J.; Macdonald, J. E. Real-Time Investigation of Crystallization and Phase-Segregation Dynamics in P3HT:PCBM Solar Cells During Thermal Annealing. Adv Funct Mater 2011, 21 (9), 1701-1708.

20. Zhao, Y.; Xie, Z.; Qu, Y.; Geng, Y.; Wang, L. Solvent-vapor treatment induced performance enhancement of poly(3-hexylthiophene):methanofullerene bulk-heterojunction photovoltaic cells. Appl Phys Lett 2007, 90 (4), 043504. 
21. Miller, S.; Fanchini, G.; Lin, Y.-Y.; Li, C.; Chen, C.-W.; Su, W.-F.; Chhowalla, M. Investigation of nanoscale morphological changes in organic photovoltaics during solvent vapor annealing. J Mater Chem 2008, 18 (3), 306-312.

22. Verploegen, E.; Miller, C. E.; Schmidt, K.; Bao, Z.; Toney, M. F. Manipulating the Morphology of P3HT-PCBM Bulk Heterojunction Blends with Solvent Vapor Annealing. Chem Mater 2012, 24 (20), 3923-3931.

23. Kim, S.; Kang, B.; Lee, M.; Lee, S. G.; Cho, K.; Yang, H.; Park, Y. D. Sequential solvent casting for improving the structural ordering and electrical characteristics of polythiophene thin films. $R s c A d v$ 2014, 4 (77), 41159-41163.

24. Müller-Buschbaum, P.; Gutmann, J. S.; Wolkenhauer, M.; Kraus, J.; Stamm, M.; Smilgies, D.; Petry, W. Solvent-Induced Surface Morphology of Thin Polymer Films. Macromolecules 2001, 34 (5), 1369-1375.

25. Xu, L.; Sharma, A.; Joo, S. W. Dewetting of Stable Thin Polymer Films Induced by a Poor Solvent: Role of Polar Interactions. Macromolecules 2012, 45 (16), 6628-6633.

26. DeSimone, J. M. Practical Approaches to Green Solvents. Science 2002, 297 (5582), 799803.

27. Nishikawa, K.; Tanaka, I.; Amemiya, Y. Small-angle x-ray scattering study of supercritical carbon dioxide. J. Phys. Chem. 1996, 100, 418-421.

28. Simeoni, G. G.; Bryk, T.; Gorelli, F. A.; Krisch, M.; Ruocco, G.; Santoro, M.; Scopigno, T. The Widom line as the crossover between liquid-like and gas-like behaviour in supercritical fluids. Nat Phys 2010, 6 (7), 503-507. 
29. Koga, T.; Seo, Y. S.; Zhang, Y. M.; Shin, K.; Kusano, K.; Nishikawa, K.; Rafailovich, M. H.; Sokolov, J. C.; Chu, B.; Peiffer, D.; Occhiogrosso, R.; Satija, S. K. Density-fluctuationinduced swelling of polymer thin films in carbon dioxide. Phys Rev Lett 2002, 89 (12).

30. Koga, T.; Seo, Y. S.; Shin, K.; Zhang, Y.; Rafailovich, M. H.; Sokolov, J. C.; Chu, B.; Satija, S. K. The role of elasticity in the anomalous swelling of polymer thin films in density fluctuating supercritical fluids. Macromolecules 2003, 36 (14), 5236-5243.

31. Koga, T.; Seo, Y. S.; Hu, X.; Shin, K.; Zhang, Y.; Rafailovich, M. H.; Sokolov, J. C.; Chu, B.; Satija, S. K. Dynamics of polymer thin films in supercritical carbon dioxide. Europhys Lett 2002, 60 (4), 559-565.

32. Sirard, S. M.; J., Z. K.; Sanchez, L. C.; Green, P. F.; Johnston, K. P. Macromolecules 2002, 35, 1928.

33. Koga, T.; Ji, Y.; Seo, Y. S.; Gordon, C.; Qu, F.; Rafailovich, M. H.; Sokolov, J. C.; Satija, S. K. Neutron reflectivity study of glassy polymer brushes in density fluctuating supercrifical carbon dioxide. J Polym Sci Pol Phys 2004, 42 (17), 3282-3289.

34. Li, Y.; Park, E. J.; Lim, K. T. L.; Johnston, K. P.; Green, P. F. Role of interfacial interactions on the anomalous swelling of polymer thin films in supercritical carbon dioxide. Journal of Polymer Science Part B: Polymer Physics 2007, 45 (11), 1313-1324.

35. Li, X. X.; Vogt, B. D. Impact of thickness on $\mathrm{CO} 2$ concentration profiles within polymer films swollen near the critical pressure. Polymer 2009, 50 (17), 4182-4188. 
36. Koga, T.; Gin, P.; Yamaguchi, H.; Endoh, M.; Sendogdular, L.; Kobayashi, M.; Takahara, A.; Akgun, B.; Satija, S. K.; Sumi, T. Generality of Anomalous Expansion of Polymer Chains in Supercritical Fluids Polymer 2011, 52, 4331-4336.

37. Mendoza-Galvan, A.; Trejo-Cruz, C.; Solis-Canto, O.; Luna-Barcenas, G. Effect of a temperature gradient on ellipsometry measurements in supercritical CO2. J. Supercrit. Fluids 2012, 64, 25-31.

38. Koo, J.; Koga, T.; Li, B.; Satija, S. K.; Rafailovich, M. H. Extending the Anomalous Dilation in CO2 to Thick Polymer Blend Films: A Neutron Reflectivity Study. Macromolecules 2016, 49 (9), 3433-3441.

39. Nishikawa, K.; Morita, T. Inhomogeneity of molecular distribution in supercritical fluids. Chem. Phys. Lett. 2000, 316, 238-242.

40. Chen, Z.; Tozaki, K.; Nishikawa, K. Evaluation and countermeasures of convective heat transfer on thermal conductivity measurement using the Peltier effect and application to supercritical CO2. Jpn. J. Appl. Phys. 1999, 38, 6840-6845.

41. Carome, E. F.; Cykowski, C. B.; havlice, J. F.; Swyt, D. A. Physica 1968, 38, 307.

42. Eckert, C. A.; Ziger, D. H.; Johnston, K. P.; Kim, S. Solute partial molar volumes in supercritical carbon dioxide. J. Phys. Chem. 1986, 90, 2738-2746.

43. Eckert, C. A.; Kuntson, B. L.; Debenedetti, P. G. Supercritical fluids as solvents for chemical and material processing. Nature 1996, 383, 313-318. 
44. Wissinger, R. G.; Paulaitis, M. E. Swelling and Sorption in Polymer-CO2 Mixtures at Elavated Pressures. J. Poly. Sci. Polym. Phys. Ed. 1987, 25, 2497-2510.

45. Goel, S. K.; Beckman, E. J. Plasticization of poly(methyl methacrylate) networks by supercritical carbon dioxide. Polymer 1993, 34, 1410-1417.

46. McHugh, M. A.; Krukonis, V. Supercritical Fluids Extraction Principles and Practice; Woburn, MA1994.

47. Condo, P. D.; Paul, D. R.; Johnston, K. P. Glass Transitions of Polymers with Compressed Fluid Diluents: Type II and III Behavior. Macromolecules 1994, 27, 365-371.

48. Koga, T.; Seo, Y. S.; Jerome, J.; Ge, S.; Rafailovich, M. H.; Sokolov, J. C.; Chu, B.; Seeck, O. H.; Tolan, M.; Kolb, R. Low-density Polymer Thin Film Formation in Supercritical Carbon Dioxide. Appl. Phys. Lett. 2003, 83, 4309.

49. Gin, P.; Asada, M.; Endoh, M. K.; Gedelian, C.; Lu, T.-M.; Koga, T. Introduction of molecular scale porosity into semicrystalline polymer thin films using supercritical carbon dioxide. Appl Phys Lett 2009, 94 (12), 121908.

50. Lan, Q.; Yu, J.; Zhang, J.; He, J. Enhanced Crystallization of Bisphenol A Polycarbonate in Thin and Ultrathin Films by Supercritical Carbon Dioxide. Macromolecules 2011, 44 (14), 5743-5749.

51. Yamaguchi, H.; Gin, P.; Arita, H.; Kobayashi, M.; Bennett, S.; Satija, S. K.; Asada, M.; Koga, T.; Takahara, A. Effect of supercritical carbon dioxide on molecular aggregation states of side chains of semicrystalline poly\{2-(perfluorooctyl)ethyl acrylate\} brush thin films. Rsc Adv 2013, 3 (14), 4778-4785. 
52. Asada, M.; Jiang, N.; Sendogdular, L.; Sokolov, J.; Endoh, M. K.; Koga, T.; Fukuto, M.; Yang, L.; Akgun, B.; Dimitriou, M.; Satija, S. Melt crystallization/dewetting of ultrathin PEO films via carbon dioxide annealing: the effects of polymer adsorbed layers. Soft Matter 2014, 10 (34), 6392-6403.

53. Jiang, N.; Sendogdular, L.; Di, X.; Sen, M.; Gin, P.; Endoh, M. K.; Koga, T.; Akgun, B.; Dimitriou, M.; Satija, S. Effect of $\mathrm{CO} 2$ on a Mobility Gradient of Polymer Chains near an Impenetrable Solid. Macromolecules 2015, 48 (6), 1795-1803.

54. Jiang, N.; Shang, J.; Di, X.; Endoh, M. K.; Koga, T. Formation Mechanism of HighDensity, Flattened Polymer Nanolayers Adsorbed on Planar Solids. Macromolecules 2014, 47 (8), 2682-2689.

55. Condo, P. D.; Sanchez, I. C.; Panayiotou, C. G.; Johnston, K. P. Glass transition behavior including retrograde vitrification of polymers with compressed fluid diluents. Macromolecules 1992, 25 (23), 6119-6127.

56. Zhang, Z.; Handa, Y. P. $\mathrm{CO}_{2}$-Assisted Melting of Semicrystalline Polymers. Macromolecules 1997, 30 (26), 8505-8507.

57. Sirard, S. M.; Gupta, P. R.; Russell, T. P.; Watkins, J. J.; Green, P. F.; Johnson, K. P. Macromolecules 2003, 36, 3365-3373.

58. Huang, F. H.; Li, M. H.; Lee, L. L.; Starling, K. E.; Chung, F. T. H. J. Chem. Eng. Jpn. 1985, $18,490-496$.

59. Russell, T. P. X-ray and neutron reflectivity for the investigation of polymers. Mater. Sci. Rep. 1990, 5 (4), 171-271. 
60. Kienzle, P. A.; O'Donovan, K. V.; Ankner, J. F.; Berk, N. F.; Majkrzak, C. F. http://www.ncnr.nist.gov/reflpak.

61. Milner, S. T.; Witten, T. A.; Cates, M. E. Theory of the grafted polymer brush. Macromolecules 1988, 21 (8), 2610-2619.

62. Sumi, T.; Sekino, H. A cooperative phenomenon between polymer chain and supercritical solvent: Remarkable expansions of solvophobic and solvophilic polymers. J. Chem. Phys. 2005, 122, 194910-1-11.

63. Sumi, T.; Imazaki, N.; Sekino, H. Critical Casmir effect in a polymer chain in supercritical solvents. Phys. Rev. E 2009, 79, 030801.

64. Tucker, S. C. Solvent Density Inhomogeneties in Supecritical Fluids. Chem. Rev. 1999, 99, 391-418.

65. Asada, M.; Gin, P.; Endoh, M. K.; Satija, S. K.; Taniguchi, T.; Koga, T. Directed selfassembly of nanoparticles at the polymer surface by highly compressible supercritical carbon dioxide. Soft Matter 2011, 7 (19), 9231-9238.

66. Kohn, P.; Rong, Z.; Scherer, K. H.; Sepe, A.; Sommer, M.; Mu“ller-Buschbaum, P.; Friend, R. H.; Steiner, U.; Hu“ttner, S. Crystallization-Induced 10-nm Structure Formation in $\mathrm{P} 3 \mathrm{HT} / \mathrm{PCBM}$

Blends. Macromolecules 2013, 46, 4002-4013.

67. Scherrer, P. Bestimmung der Grösse und der inneren Struktur von Kolloidteilchen mittels Röntgenstrahlen. Nachr. Ges. Wiss. Göttingen 1918, 26, 98-100. 
68. Cho, S.; Lee, K.; Yuen, J.; Wang, G.; Moses, D.; Heeger, A. J.; Surin, M.; Lazzaroni, R. Thermal annealing-induced enhancement of the field-effect mobility of regioregular poly(3hexylthiophene) films. J Appl Phys 2006, 100 (11), 114503.

69. Park, Y. D.; Lee, H. S.; Choi, Y. J.; Kwak, D.; Cho, J. H.; Lee, S.; Cho, K. SolubilityInduced Ordered Polythiophene Precursors for High-Performance Organic Thin-Film Transistors. Adv Funct Mater 2009, 19 (8), 1200-1206.

70. Lampert, M. A.; Mark, P. Current injection in solids; Academic Press1970.

71. Nam, C.-Y.; Su, D.; Black, C. T. High-Performance Air-Processed Polymer-Fullerene Bulk Heterojunction Solar Cells. Adv Funct Mater 2009, 19 (22), 3552-3559.

72. Nam, C.-Y. Facile Determination of Bulk Charge Carrier Concentration in Organic Semiconductors: Out-of-Plane Orientation Hopping Conduction Characteristics in Semicrystalline Polythiophene. The Journal of Physical Chemistry C 2012, 116 (45), 2395123956.

73. Kokubu, R.; Yang, Y. Vertical phase separation of conjugated polymer and fullerene bulk heterojunction films induced by high pressure carbon dioxide treatment at ambient temperature. Phys Chem Chem Phys 2012, 14 (23), 8313-8318.

74. Abdou, M. S. A.; Orfino, F. P.; Son, Y.; Holdcroft, S. Interaction of Oxygen with Conjugated Polymers: Charge Transfer Complex Formation with Poly(3-alkylthiophenes). J Am Chem Soc 1997, 119 (19), 4518-4524. 
75. Meijer, E. J.; Detcheverry, C.; Baesjou, P. J.; van Veenendaal, E.; de Leeuw, D. M.; Klapwijk, T. M. Dopant density determination in disordered organic field-effect transistors. $J$ Appl Phys 2003, 93 (8), 4831-4835.

76. Meijer, E. J.; Mangnus, A. V. G.; Huisman, B. H.; 't Hooft, G. W.; de Leeuw, D. M.; Klapwijk, T. M. Photoimpedance spectroscopy of poly(3-hexyl thiophene) metal-insulatorsemiconductor diodes. Synthetic Met 2004, 142 (1-3), 53-56.

77. Liao, H.-H.; Yang, C.-M.; Liu, C.-C.; Horng, S.-F.; Meng, H.-F.; Shy, J.-T. Dynamics and reversibility of oxygen doping and de-doping for conjugated polymer. J Appl Phys 2008, 103 (10), 104506.

78. Frenkel, J. On Pre-Breakdown Phenomena in Insulators and Electronic Semi-Conductors. Physical Review 1938, 54 (8), 647-648.

79. Horowitz, G.; Hajlaoui, R.; Fichou, D.; El Kassmi, A. Gate voltage dependent mobility of oligothiophene field-effect transistors. J Appl Phys 1999, 85 (6), 3202-3206.

80. Blom, P. W. M.; de Jong, M. J. M.; Vleggaar, J. J. M. Electron and hole transport in poly(p - phenylene vinylene) devices. Appl Phys Lett 1996, 68 (23), 3308-3310. 


\section{For Table of Contents use only}

"Novel effects of compressed $\mathrm{CO}_{2}$ molecules on structural ordering and charge transport in conjugated poly(3-hexylthiophene) thin films"

Naisheng Jiang, Levent Sendogdular, Mani Sen, Maya K. Endoh, Tadanori Koga, Masafumi Fukuto, Bulent Akgun, Sushil K. Satija' Chang-Yong Nam



